\title{
Psychiatric Evaluation of Chronic Diarrhea: A Case Report
}

\author{
Moien Kardoust ${ }^{1}$, Pouria Yazdian-Anari ${ }^{2}$, Mostafa Nasiripour ${ }^{1}$, Reza Bidaki $^{3}$, * \\ ${ }^{1}$ Student Research Committee, Rafsanjan University of Medical Sciences, Rafsanjan, Iran \\ ${ }^{2}$ Student Research Committee, Shahid Sadoughi University of Medical Sciences, Yazd, Iran \\ ${ }^{3}$ Research Center of Addiction and Behavioral Sciences, Shahid Sadoughi University of Medical Sciences, Yazd, Iran
}

*Corresponding Author: Reza Bidaki, Research Center of Addiction and Behavioral Sciences, Shahid Sadoughi University of Medical Sciences, Yazd, Iran. Tel: +98-0353-26223555, Fax: +98-0353-2632004, Email: Reza_bidaki@ yahoo.com

Received: 12 Jul. 2015; Accepted: 25 Sep. 2015; Online Published: 11 Jan. 2016

\begin{abstract}
Introduction: Diarrhea is one of the most common symptoms treated in general practice and gastroenterology. An estimated 1.7 billion cases of diarrhea are reported annually. Anxious and emotional persons are more sensitive to digestive problems. Anxious persons may feel their heartbeat and perceive their intestinal motility and spasm, and this may cause them more concern.

Case Presentation: In this case report, a 31-year-old woman with chronic diarrhea and a stressed psyche is presented so as to emphasize the combination of organ disorders and psychiatric moods.

Conclusion: Patients suffering from chronic and persistence gastrointestinal disease should be evaluated by a psychiatrist. Psychotherapy and psych pharmacotherapy can greatly help the treatment of somatic complaints of these patients.
\end{abstract}

Keywords: Gastrointestinal Disease, Emotions, Anxiety, Diarrhea

\section{Introduction}

Diarrhea is one of the most common symptoms seen in general practice and gastroenterology. An estimated 1.7 billion cases of diarrhea are reported annually [1]. Diarrhea that lasts for more than 4 weeks is considered chronic [2]. The prevalence of chronic diarrhea ranges $4-14 \%$ according to population age and country $[3,4]$.

Chronic diarrhea has many differential diagnoses and is categorized into three groups: 1. Watery, 2. Fatty, and 3. Inflammatory diarrhea [5].

In this paper, the case of a 31-year-old woman with chronic diarrhea and a stressful psychiatric condition is presented. The purpose of presenting this case is to emphasize the combination of organ disorders and psychiatric moods.

\section{Case Presentation}

The patient is a 31-year-old female who began suffering from abdominal pain 13 years ago, six months after her marriage. She was referred to a surgeon after visiting a subspecialist of gastroenterology. After abdominal imaging, the surgeon noticed two small intestinal cysts which were later surgically removed. Pathology reports of the cysts rejected Crohn's disease and ulcerative colitis. The patient was recovering, but developed diarrhea two months after surgery. Her diarrhea was watery, but neither bloody nor painful. According to the patient's statement, she experienced this problem continuously for 2.3 of each week. No problem was reported after re-examination by the surgeon. She suffered from infertility, but that problem was resolved without treatment, and she now has two children. The patient stated that during her pregnancy, she recovered fully from the diarrhea, but symptoms returned after she had given birth. Her diarrhea was more severe in spring and fall. The patient weighed $40 \mathrm{~kg}$, but stool, blood count, and blood biochemistry test results were normal. She suffered from neither thyroid problems nor malabsorption, and there were no signs of symptoms related to irritable bowel syndrome. Therefore, she was referred to a neurologist. The patient looked anxious during the neurological and psychiatric examination, but she wasn't in a depressed mood.

The patient was under treatment by a subspecialist of gastrointestinal diseases who prescribed one pancreatin tablet to be taken twice daily, metronidazole pills $250 \mathrm{mg}$ TDS, and cholestyramine powder one pack/day for 5 months. At the end of treatment, the patient was not cured. Her psychiatrist prescribed Doxepine $25 \mathrm{mg}$ every night, 10 mg propranolol every 12 hours, and risperidone $0.5 \mathrm{mg}$ every night. A month after her primary visit to the psychiatrist, the patient's gastrointestinal symptoms, anxiety, and worry about the disease had improved, and she said that she had never felt better.

\section{Discussion}

Anxiety is a response to external stress which can occur mentally or physically. This type of feeling arises from brain amygdalae that are responsive to most sentiments. In other words, anxiety prepares one for critical situations, but it may adversely affect the body and result in headache, nausea, diarrhea, and frequent urination; if not treated, it can damage both the body and the mind [6]. Anxious and emotional persons are more sensitive to digestive problems. Anxious persons may feel their heartbeat and perceive their intestinal motility and spasm, and this may cause them greater concern.

The authors believe that any factor that reduces stress can mitigate this vicious cycle and result in the treatment of patients. Therapeutic methods including relaxation, music, shopping, regular exercise, enough sleep, and modifying certain behaviors and dietary habits can be helpful. Having a correct understanding of anxiety can help in the treatment of organic disorders [7]. 
There are no precise statistics about anxiety problems in individuals with digestive diseases. A study in New Zealand on patients with gastroenteritis concluded that high incidence of anxiety and the occurrence of IBS can result in an inflammatory disease [8].

Medicinal treatment is less valued than psychotherapy; however, if applied simultaneously, they can aid in providing a more rapid recovery and relief from symptoms. Drugs most commonly used in patients of chronic diarrhea include anxiolytic drugs, anti-depressants, and betablockers [9].

It seems that the more chronic and long-lasting the disease is, the more anxiety and adverse effects patients will experience. Patients may confuse the signs of anxiety with a serious or dangerous disease, and this can result in greater psychological and medical problems [10].

For example, the resection of a part of the intestine due to a cyst or necrosis, even if not due to a malignancy, may direct a person's attention toward many issues, for instance, is there a malignancy? Can intestinal resection produce more serious problems? Am I obliged to change my dietary habits? Will all nutrients be absorbed correctly into my body? Will I have any deficiency in this regard?

\section{Conclusion}

Patients suffering from chronic digestive disease should be psychologically evaluated in detail. Psychotherapy can greatly help the treatment of physical problems in these patients.

\section{Acknowledgments}

The authors would like to thank the patient for her cooperation and Dr. Vahid Mirzaei (Gastrointestinal subspecialist in Rafsanjan City) for the patient referral.

\section{Authors' Contributions}

All authors contributed extensively to the work presented in this paper.

\section{Conflicts of Interest}

None.

\section{References}

1. Mandaliya R, Auerbach H, Mehta P. A Challenging Cause of Chronic Diarrhea. Gastroenterology. 2015;148(1):28-9. [DOI]

2. Aranda-Michel J, Giannella RA. Acute diarrhea: a practical review. Am J Med. 1999;106(6):670-6. [DOI]

3. Abdullah M, Firmansyah MA. Clinical approach and management of chronic diarrhea. Acta Med Indones. 2013;45(2):157-65.

4. Lee KS, Kang DS, Yu J, Chang YP, Park WS. How to do in persistent diarrhea of children?: concepts and treatments of chronic diarrhea. Pediat Gastroenterol Hepatol Nutr. 2012;15(4):229-36. [DOI]

5. Valenzuela RS. [Chronic diarrhea]. Rev Gastroenterol Mex. 2006;71 Suppl 1:83-5.

6. Csef H, Bornhauser N. Psychosomatic aspects of chronic diarrhea. MMW Fortschr Med. 2003;145(50):35.

7. Hammond DC. Hypnosis in the treatment of anxiety-and stressrelated disorders. Expert Rev Neurother. 2010;10(2):263-73. [DOI]

8. Spiller R, Aziz Q, Creed F, Emmanuel A, Houghton L, Hungin P, et al. Guidelines on the irritable bowel syndrome: mechanisms and practical management. Gut. 2007;56(12):1770-98. [DOI]

9. Kamrowska A, Kasprzak K, Marciniak J, Goch A, Kamrowski C. [Anxiety and depression in ulcerative colitis and LesniovskyCrohn's disease]. Pol Merkur Lekarski. 2010;28(165):239-41.

10. Bannaga AS, Selinger CP. Inflammatory bowel disease and anxiety: links, risks, and challenges faced. Clin Exp Gastroenterol. 2015;8:111-7. [DOI] 